\title{
EL AMIGO INVISIBLE. UNA APROXIMACIÓN AL SIDA A TRAVÉS DE LA OBRA DE HERVÉ GUIBERT
}

\section{The Invisible Friend. An approach to AIDS through the Work of Hervé Guibert}

\author{
Laura POLÁN; Javier CACHERO \\ Universidad de Oviedo. Facultad de Medicina y Ciencias de la Salud (España). \\ Correos electrónicos: U0276757@uniovi.es; lauramedpolan@gmail.com
}

Fecha de recepción: 10 de septiembre de 2020

Fecha de aceptación: 14 de septiembre de 2020

Fecha de publicación: 29 de enero de 2021

\begin{abstract}
Resumen
En plena pandemia de VIH/SIDA que asolaba de manera silenciosa el mundo, Hervé Guibert publicó en 1990 "Al amigo que no me salvó la vida". Guibert plantea esta novela a modo de despedida personal. En ella, el autor pretende exponer la dureza de la enfermedad, narrando con total sinceridad y claridad cuestiones tales como causas de infección, sintomatología, tratamiento y pronóstico de la enfermedad y los aspectos socioculturales que implican estar enfermo de VIH en la década de los 80 , en donde la ignorancia acerca del tema provocó una repulsa inmediata hacia los afectados. Hervé escribe la novela en una época donde millones de enfermos languidecían en sus casas apartados y repudiados con el objetivo de educar y visibilizar la situación de los enfermos de VIH. La incertidumbre, la ignorancia, el dolor y la falta de empatía son temas recurrentes en la narración, cuyo autor aborda a la par como, testimonio personal y acción reivindicativa. En definitiva, pretende con esta publicación remover conciencias y dar voz a los millones de almas que deambularon desamparados y sin más certeza que la de su futura muerte por una sociedad asustada por el desconocimiento acerca del VIH. Desconocimiento que el autor aspira a suprimir con su novela. Finalmente, Hervé Guibert, fallecerá a causa del SIDA a la edad de 36 años en 1991
\end{abstract}

Rev. Med. Cine. 2020; 16 (e), 453-468 Ediciones Universidad de Salamanca / @®@ J. Med. Mov., 2020; 16 (e), $453-468$ 
dejando un legado que nos hace recordar la necesidad de luchar contra la estigmatización de los enfermos y las enfermedades.

Palabras clave: VIH: SIDA; epidemia; Hervé Guibert; rechazo social.

\section{Abstract}

In 1990, in the middle of the HIV/AIDs pandemic which was devastating silently the World, Herve Guibert published "To the friend who did not save my life". Guibert outline the novel as a personal farewell. In the novel, the author wants to explain the harshness of the disease, telling with total honesty and openess issues such as causes, symptomatology, treatment and prediction of the IHV and the sociocultural aspects which an IHV patient has to deal with. Specially, in the 80 's when ignorance about the matter caused an immediate condemnation against sick people. Herve wrote the story in a period of time in which millions of patients languished at their homes, in order to educate and make the VIH patients condition visible. The uncertainty, the ignorance, the pain and the lack of empathy are recurring matters in the novel, whose author tackles at the same time as a personal testimony and activist action. In conclusion, he tries to raise awareness and to give voice to the millions of helpless souls that wandered through a society frightened because of the ignorance about IHV, with only the conviction of their future death. In 1991, Herve Guibert will die due to AIDs at the age of 36 leaving a legacy which reminds us the need of keep fighting against the stigma.

Keywords: HIV; AIDS; epidemic; Hervé Guibert; social rejection.

"Le besaré las manos a quien me anuncie que estoy desahuciado"

"Un cáncer que sólo afectaría a los homosexuales, no, sería demasiado bello para que fuese verdad... iEs para morirse de la risa!"

(Hervé Guibert, "Al amigo que no me salvó la vida")'

\section{INTRODUCCIÓN}

Si nos centramos en la temática general de la que trata este número, podemos ver que la RAE define el concepto "Epidemia" con dos acepciones, por un lado, "se dice de aquella enfermedad que se propaga durante algún tiempo por un país, acometiendo simultáneamente a gran número de personas" y a su vez "se dice de un mal o daño que se expande de forma intensa $e$ indiscriminada". Partiendo de esto, podemos preguntarnos en qué momentos de la historia se ha considerado, que se estaba produciendo un acontecimiento tal, que podría acogerse bajo el término "Epidemia". No debemos olvidar que la enfermedad siempre ha formado parte de la historia de la humanidad de manera intrínseca².

El hombre, desde sus orígenes, siempre ha reaccionado ante las enfermedades contagiosas con un sentimiento claro de pánico; el cual le lleva a tratar de escapar de ese mal que acecha. Ya en las primeras pandemias los sabios se percataron de la facilidad de contagio que estas enfermedades acarreaban y por ello se recurría al aislamiento, lo que en nuestros días conocemos como "el confinamiento", pues se decía que los enfermos "irradiaban el mal". "La cuarentena" (ese tan popular cordón sanitario) tampoco es un invento de nuestros días, sino que tiene su origen en Italia y deriva de la expresión "Quaranta giorni"3, que era la cuarentena a la que se sometían los barcos que llegaban a puerto durante la epidemia de peste negra de Florencia del siglo XIV, para asegurarse de que ninguno de sus tripulantes estuviera enfermo. 
Si nos centramos en las causas de las epidemias nos vemos en la obligación de hacer alusión a la peste, pues ha sido, sin duda, responsable de grandes catástrofes a lo largo de la historia de la humanidad. Destacan oleadas de peste como la Peste de Cipriano (Siglo III d. C.), la de Justiniano (Siglo VI d. C.), la famosísima Peste Negra (13471382) que en la Edad Media dejó en torno a 25 millones de muertos, la del siglo XVI que asoló Italia y Alemania, la de Inglaterra el 1665 o la de Viena en $1678^{4}$.

Si echamos un vistazo a nuestra actualidad más reciente (pasando por alto nuestra actual pandemia global de COVID-19) una de las pandemias más importantes es la que experimentó un boom en el siglo XX, la pandemia el VIH/SIDA (Síndrome de inmunodeficiencia adquirida).

En 1970 empezaron a darse casos de una aparente nueva enfermedad cuyas manifestaciones sorprendieron a la cúpula científica de la época. Los Centros para el Control de Enfermedades (CDC) de Atlanta pusieron de manifiesto el gran número de casos y focos epidémicos, surgiendo hipótesis sobre el origen de la infección achacando su presencia en EE. UU. a los haitianos infectados que emigraban al país ${ }^{5}$. Esta patología se denominó GRID "gay-related inmune deficiency" (inmunodeficiencia relacionada a homosexuales) o cáncer gay y muchas personas consideraban el actual SIDA como un castigo divino ${ }^{6}$. Hasta el desarrollo, en la década de los noventa, del tratamiento combinado de alta eficacia, le epidemia atravesó la llamada "fase de la devastación" debido a que el único pronóstico era la muerte. Inicialmente se le denominó la "enfermedad de las $4 \mathrm{H}^{\prime \prime}$ debido a la alta prevalencia de le enfermedad en homosexuales, heroinómanos, haitianos y hemofílicos, generando la falsa creencia de que solo afectaba a dichos grupos. No obstante, la expansión de la enfermedad hizo que este pensamiento fuera desechado ${ }^{5}$.
En la actualidad, existe un tratamiento que permite cronificar la enfermedad y negativizar la analítica. No obstante, los ecos de la epidemia no se han apagado, dado que aún es elevado el número de muertes actuales, de las que puede hacerse responsable a la no observación de medidas de prevención, y a la dificultad de acceder a los tratamientos en los países con menores recursos económicos.

Con este artículo buscamos dar visibilidad a la incertidumbre que rodeó a los primeros años de la pandemia del SIDA, aunque el desconcierto acerca de esta enfermedad sigue vigente hoy en día. Con este fin nos apoyaremos en el mensaje contenido en la obra de Hervé Guibert titulada "Al amigo que no me salvó la vida".

\section{Biografía y obra de HeRVÉ GUIBERT}

Hervé Guibert nació en Saint-Cloud (Francia) el 14 de diciembre de 1955. Conocido sobre todo por su obra literaria, cultivó también la fotografía y el cine. Empezó a labrarse un nombre con una columna sobre fotografía que escribió para el periódico Le Monde entre 1977 y 1985. Con 22 años publicó su primer libro "La mort propagande"; autorretrato premonitorio sobre su enfermedad y futura muerte. En 1984, obtiene el premio César al mejor guion por L'Homme blessé (El hombre herido). Es en 1990 cuando se publica en Francia "Al amigo que no me salvó la vida"; novela autobiográfica en donde Guibert narra sobre "la historia del SIDA, del tiempo de la incubación, de la enfermedad y de los ochenta...". En ella, no solo se centra en la relación con su propia enfermedad, si no que muestra también el proceso de la enfermedad de sus amigos como el filósofo Michel Foucault cuyo nombre ficticio es Muzil. El amigo del título es el personaje denominado en la novela como Bill que había prometido al autor suministrarle una posible cura y por tanto salvarle la vida, de ahí la frase "durante tres meses tuve el SIDA" haciendo referencia a la 


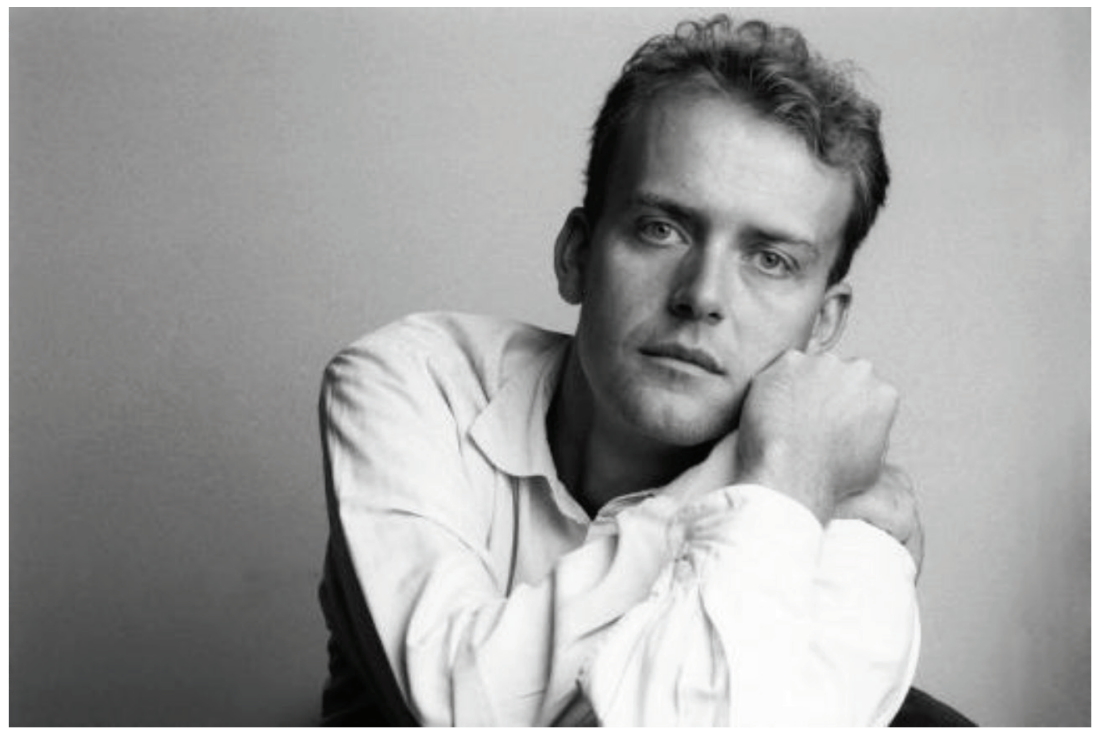

Imagen 1. Fotografía de Hervé Guibert. París, septiembre de 1988.

esperanza de curarse. Promesa que fue incumplida. También relata cómo evoluciona la relación de los demás con los nuevos "apestados". En definitiva, en su novela son constantes temas como la degradación física, la muerte y la crítica a la sociedad del momento. Hervé Guibert morirá en 1991 a los 36 años, víctima del SIDA, no sin antes dejar por escrito una novela que, aunque fue escandalosa en su momento, contribuyó a luchar contra el estigma y el tabú que acompañaba al $\mathrm{VIH}^{7,8}$.

Hervé escribe la novela a modo de bastón donde apoyarse, a modo de un refugio en donde esconderse, también para romper tabúes, tanto por afirmar en la obra que era homosexual como por revelar la enfermedad que padecía; recordemos que ambas cosas eran causa de rechazo social. También para dejar testimonio de lo vivido, qué pruebas le realizaron y qué tratamientos le administraron. Otras novelas del autor son "El protocolo compasivo", continuación de "Al amigo que no me salvo la vida", en donde continúa narrando la evolución del VIH.
Un clásico de la literatura sobre enfermedad es analizar la razón por la cual un autor decide dejar constancia de su historia personal en la vivencia de la enfermedad ${ }^{9}$. Desde esta óptica podemos preguntarnos, respecto a Hervé y "Al amigo que no me salvó la vida", ¿’por qué narrar tu caída? Una respuesta evidente sería que la finalidad es no sentirte solo en el momento más duro de tu vida, lo cual no es del todo altruista. También para dejar testimonio sobre aspectos que rodearon a esta enfermedad y que por ello son relevantes, porque nos permiten saber que se hacía mal y que sabemos ahora que realmente funciona.

\section{MATERIAL Y MÉTOdOS}

El trabajo realizado ha tomado de base la novela "Al amigo que no me salvó la vida" del autor francés Hervé Guibert. Para documentar el tema se ha recurrido a bibliotecas virtuales de carácter científico tales como SciELO, usando como palabras clave "VIH", "SIDA", "Antirretrovirales"... 
Se ha realizado una lectura analítica del libro a lo largo de la que hemos identificado los aspectos relacionados con la enfermedad central que se analiza en el mismo, así como los aspectos sociales, asistenciales y humanos que se describen. La información seleccionada se extrajo en una base documental confeccionada al efecto en la que se organizaron en distintas categorías. Así mismo se anotaron aquellos aspectos que resultaron nuevos en la presentación de la enfermedad, cuáles fueron las incertidumbres que generó, los abordajes que se realizaron para su resolución y que desarrollos científicos y médicos aportó al futuro de la medicina.

\section{RESULTADOS}

El VIH fue descubierto en 1983, por Françoise Barré-Sinoussi y Luc Montagnier en el Instituto Pasteur de París y posteriormente en 1984 por Robert Gallo en el Instituto Nacional de Cáncer en Bethesda, EE. UU. Después de una polémica sobre la autoría del descubrimiento, en 1986 se acordó la denominación de virus de la inmunodeficiencia humana $(\mathrm{VIH})^{10}$.

EI VIH pertenece a la familia de los lentivirus y se clasifica en dos tipos: VIH-1 y VIH-2 que presentan en torno al $40 \%$ de homología genética. Los lentivirus son retrovirus exógenos que causan infecciones persistentes dando lugar a enfermedades con largos periodos de incubación. Estos virus infectan células del sistema inmune como macrófagos y células T. Los lentivirus tienen un genoma de ácido ribonucleico (RNA) y tienen la capacidad de codificar genes esenciales que permiten la regulación de su propia expresión en la célula infectada. Su replicación implica la posterior muerte de la célula.

EI VIH-1, con mayor capacidad patogénica, fue el responsable de la pandemia mundial de SIDA, mientras que el $\mathrm{VIH}-2$ se encuentra de forma endémica en el África Occidental, aunque hay casos aislados en Europa y América. El origen de ambos se debe a saltos filogenéticos de virus que infectan a simios en África. Las diferentes cepas del VIH-1 se han dividido en tres clases según su homología: el grupo $M$ (main), el $O$ (outlier) y el grupo $\mathrm{N}$ (no $\mathrm{M}$, no O). A su vez, el grupo $M$ presenta 9 subclases $(A, B, C, D, E, F$, $G, H, J, K)$, y en cepas recombinantes entre ellos, denominados CRF (formas recombinantes circulantes). Siendo el $\mathrm{VIH}-1$ grupo $\mathrm{M}$ responsable de la pandemia del Sida ${ }^{5}$.

\section{Transmisión}

Hay numerosas hipótesis sobre el salto a la especie humana, siendo el mecanismo de exposición más probable la caza y consumo de carne de chimpancé infectado. La infección en humanos por el VIH-1 se mantuvo inicialmente limitada a poblaciones limítrofes con el río Congo, hasta que llegó a la ciudad de Kinshasa alrededor de 1930. A partir de ahí, se extendió por todo el planeta llegando a EE. UU. a principios de los 80 , a través de la población haitiana que emigró hacia el nuevo continente. La trasmisión de la enfermedad se produce de persona a persona por vías que implican el contacto con sangre o fluidos. Mayormente se debe a relaciones sexuales sin protección, siendo en el África Subsahariana y el Caribe por contacto heterosexual mientras que en Europa Occidental, EE. UU., Canadá o Australia por relaciones de hombres homo o bisexuales. También hay casos de trasmisión de madre infectada a hijo durante el embarazo, lactancia o el parto. En países sin control sanitario, la recepción de transfusiones de sangre o hemoderivados procedentes de personas infectadas son una forma importante de trasmisión. También se puede adquirir la infección al pincharse con objetos contaminados con sangre o suero, como los consumidores de heroína; vía de trasmisión predominante, actualmente, en los países bálticos, Europa del Este y Asia Central ${ }^{5}$. En un pasaje de la novela, en el que alude al contagio de uno de los personajes, el autor describe algunos de los patrones de contagio: "un día un informador proclama que pilló 
la enfermedad pinchándose con su hermano, que es un pobre yonqui; al día siguiente otra fuente de información asegura que la contaminó una transfusión sanguínea; un tercer rumor explica que fue el yanqui de su marido, que es un ligón bisexual de primera, etc.".

\section{Naturaleza y organización del virus}

El VIH-1 tiene forma de esfera de 100-120 $\mathrm{nm}$ de diámetro. Su envoltura lipídica consiste en una bicapa tomada de la membrana celular humana en el proceso de formación de nuevos viriones. En dicha envoltura encontramos proteínas transmembrana de la célula huésped como la glicoproteína Env, un hetero-dímero formado por tres glicoproteínas de superficie 120 (gp $120)$, unidas no covalentemente a un dominio transmembrana formado por tres glicoproteínas 41 (gp 41) ${ }^{11}$. Estos oligómeros son vitales para la unión de la partícula viral a las células $T$, además de permitir la identificación de la partícula a través de la microscopía electrónica. No obstante, cada partícula presenta un número pequeño de estas estructuras $14 \pm 7$, además de su fragilidad por su inestable unión, haciendo que la mayoría no sean funcionales. Por su parte, la dificultad de neutralizar la infección por VIH-1 está relaciona con Env debido a la gran variabilidad de la envoltura con 5 regiones hipervariables de gp120, la elevada glicosilación de Env que dificulta la unión de anticuerpos y el enmascaramiento conformacional, que hace referencia a que la zonas más vulnerables de Env; el sitio de unión con los co-receptores, no existe hasta que hay un cambio conformacional de la gp 120 para unirse al CD4 de los linfocitos "helpers", y es por tanto, muy difícil la neutralización por parte de los anticuerpos. Por debajo de la envoltura, la proteína miristilada MA (p17) forma la estructura icosaédrica; la matriz viral. En el centro, se encuentra la cápside con forma de cono formada por la proteína CA (p24). Dentro de la cápside, se encuentra todo el material necesario para armar la partícula vírica: las dos cadenas idénticas de RNA, un par de iniciadores de RNAt y las proteínas virales Proteasa ( $p 15)$, Retrotranscriptasa (p55 y p66), Integrasa (p11), Nucleocápside (p6). El enzima retrotranscriptasa es la responsable de convertir el RNA en DNA que será posteriormente integrado en el genoma celular. Este provirus tiene una longitud aproximada de 9,8 $\mathrm{kb}^{12}$.



Imagen 2. Estructura de la partícula viral del $\mathrm{VIH}^{5}$. 
En su genoma encontramos tres regiones codificantes, gag, pol y env. La región gag codifica la proteína de la matriz p17 y la proteína de la cápside p24 y la nucleoproteína p6. El gen pol será el responsable de la síntesis de los tres enzimas del ciclo infectivo; la proteasa (PR), la transcriptasa inversa (RT) y la integrasa (IN). Además, contiene otros seis genes denominados inicialmente accesorios: tat, rev, nef, vif, vpu y vpr con un papel muy importante en el ciclo biológico del virus ${ }^{13}$.

El proceso de infección comienza cuando la glicoproteína de superficie Env se une el receptor de superficie $C D 4$, presente mayoritariamente en los linfocitos $T$ cooperadores, linfocitos que Guibert en su libro denomina T4; los guardias cuyos niveles disminuyen a medida que avanza la ofensiva vírica. Tras la unión, se produce la introducción del material genético que sufre un proceso de retrotranscripción gracias a la RT viral que culmina con la inserción del DNA viral lineal en el genoma celular gracias a la integrasa. EI provirus integrado se organiza como una unidad transcripcional eucariótica cuya transcripción dará lugar a un transcrito primario que podrá servir o como RNA mensajero para la síntesis de proteínas virales o RNA genómico. El promotor del VIH es regulado por factores celulares y virales y su actividad varía dependiendo del estado celular. Comienza entonces un proceso de formación de millones de partículas virales acompañada de la consecuente destrucción de linfocitos $\mathrm{CD} 4+{ }^{14}$.

Esta destrucción celular linfocitaria será compensada durante varios años, hasta que las reservas corporales se agotan, llevando a la inmunodeficiencia adquirida; SIDA. Este periodo de latencia clínica varía. Los progresores típicos; el $85 \%$, como el caso de Guibert o Muzil, desarrollan el SIDA entre los seis y diez años posteriores al contagio, mientras que los rápidos lo hacen en tres o menos y los lentos en más diez. La progresión de la enfermedad se evalúa mediante la tasa de linfocitos CD4+ considerando que una

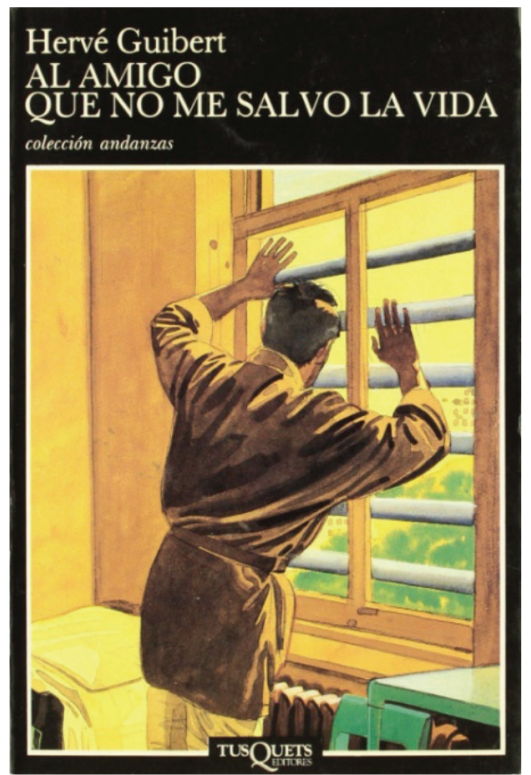

Imagen 3. Portada de la primera edición en español de Al amigo que no me salvó la vida.

Barcelona: Tusquets; 1991.

persona normal posee entre 500 y $2000 / \mathrm{mm} 3$, con la infección por VIH, y sin tratamiento, los niveles van disminuyendo hasta que se llega a la peligrosa barrera de los 200, momento a partir del cual pueden aparecer enfermedades oportunistas, que termina con la vida del enfermo ${ }^{15}$.

En la década de los 80, el AZT fue el único medicamento existente que conseguía alargar la última etapa del enfermo. Actualmente, existe un importante arsenal terapéutico que permite cronificar la enfermedad y reducir la mortalidad ${ }^{16}$.

Las enseñanzas de Al Amigo que no me salvo la vida

El protagonista de esta historia, Hervé, padece SIDA, una patología muy desconocida en su época, causada por VIH. Este virus se transmite entre individuos a través de fluidos corporales tales como el semen, las secreciones vaginales, la sangre o la leche materna; también puede darse 
una infección del feto si la gestante se encuentra infectada, hecho que aparece reflejado en la novela. La primera víctima de este virus de la que se nos habla es un gran amigo de Hervé llamado Muzil del cual sabemos que "Le encantaban las orgías violentas en las saunas de San Francisco las cuales hoy están vacías a causa de la pandemia". Tras tener conocimiento de la enfermedad que acababa con la vida de su amigo, Guibert está convencido de que por desgracia le sigue el mismo fin.

\section{Incertidumbre}

En cuanto al conocimiento científico se refiere, una de las cuestiones que se nos plantea a la hora de hablar sobre el VIH es ¿Cómo saber si este enemigo acérrimo se encuentra en nuestro interior? Recordemos que tal y como se comenta en la novela que nos ocupa, este virus puede presentar un tiempo de incubación variable. Si recurrimos a las fuentes con las que contamos hoy día veremos que aún hoy no se han identificados signos claros de la presencia del virus en nuestro organismo en etapas tempranas, de ahí la importancia de las practicas preventivas de evitación de conductas de riesgo. Este es uno, sino el más difícil aspecto del SIDA; podemos padecerlo o no, pero solo estaremos seguros al $100 \%$ tras realizar una prueba específica a partir de nuestra sangre.

\section{Signos y síntomas}

Algunos casos pueden presentarse como un cuadro pseudogripal las semanas posteriores a infectarse. Sin embargo, tras años sin tratamiento, sí que se detectan signos más claros que ayudan a identificar este virus como agente causal, entre ellos se encuentran pérdida de peso, fiebre, cansancio generalizado ${ }^{17}$, inflamación de ganglios linfáticos. Con mucha frecuencia el tracto gastrointestinal se ve afectado, presentando como sintomatología la diarrea crónica.
Entre los oportunistas que aprovechan la debilidad de nuestro organismo para atacar al esófago o al colon son, respectivamente, los hongos cándida y citomegalovirus ${ }^{18}$. Ya los primeros casos confirmados en Portugal, Haití, Francia...presentaban, aparte de infecciones en boca y esófago, erupciones cutáneas que respondían a una forma agresiva del Sarcoma de Kaposi y neumonías causadas por Pneumocystis jirovecii, al margen de daños neurológicos y una clara supresión de su sistema inmune ${ }^{6}$.

En 1983 Hervé se ve obligado, por unas fiebres violentas, a regresar a Francia y reducir su estancia en México. A su llegada descubre que uno de sus amantes; Jules, había sido hospitalizado por una fiebre (elevada) y presentaba el cuerpo lleno de ganglios. En estos días, tras su regreso de México, Hervé desarrolló otro signo, pues se dio la aparición de un absceso monstruoso en el fondo de la garganta de Hervé, que le impedía tragar. También sufre una drástica pérdida de peso, que al menos parcialmente, logró remediar mediante ampollas de "Trophisan", un preparado nutricional a base de aminoácidos esenciales, minerales y vitaminas. Tras estos hechos Hervé lo ratificó todo en su interior, "Los dos teníamos SIDA".

Uno de los primeros signos clínicos que se comenta es la presencia de un hongo en su lengua. Dicho oportunista le causaba unos papilomas blancos que actualmente podemos relacionar con candidiasis pseudomembranosa, la infección fúngica más frecuente en pacientes con SIDA ${ }^{19}$ que Hervé Guibert describe como "unos pequeños filamentos blanquecinos, papilomas sin espesor, estriados como aluviones sobre el tegumento de la lengua". Como tratamiento, el doctor Chandi se decantó por "Fongylone" (principio activo no identificado) y "Daktarin ${ }^{\circledR "}$ (Miconazol) ${ }^{20,21}$, dos antifúngicos de uso tópico administrados durante 21 días cada uno; sin embargo, ninguno de los dos medicamentos logró expulsar dicho hongo. En este punto, Hervé alude a la opinión de otro 
personaje, que sostiene que, cuando un paciente de SIDA presenta menos de 200 T4 aparecen ataques irreversibles sobre el organismo, tales como los agentes responsables de la Neumocistosis y la Toxoplasmosis. Ambos agentes no causan problemas importantes en individuos con el sistema inmunitario indemne, no así en los afectados por el VIH: "Los hongos de la neumocistosis, que son para los pulmones y para la respiración como una especie de boa constrictor, y los de la toxoplasmosis, que destruyen el cerebro, se hallan presentes en el interior de cada ser humano, pero el equilibrio del sistema inmunológico les impide tener derecho de ciudadanía, mientras que el SIDA las permite actuar libremente".

\section{El personal sanitario}

En su novela Hervé comenta la actividad profesional de sanitarios de los que ha recibido cuidados. Así, cita entre ellos al doctor Nacier, del que destacaba su indiscreción al cotillear sobre sus pacientes célebres; también es tratado por el doctor Levy, del que menciona que no le curó una hepatitis leve que tuvo, al tiempo que no hacía caso a sus quejas sobre un pinchazo tenaz en la parte derecha de su vientre que le hacía temer un cáncer de hígado. El médico Nocourt, por el contrario, realizó todas las pruebas posibles para dar con ese ficticio tumor; destaca una urografía que Hervé rememora con disgusto: "estuve acostado desnudo durante más de una hora sin que nadie me avisara de cuánto duraba el examen sobre una mesa metálica helada, bajo una cristalera por la que podían verme unos obreros que trabajaban en un tejado". No olvida Guibert que "El médico que me anunció el resultado me caía antipático, y recibí, por supuesto, fríamente la noticia, para quitarme de encina lo antes posible a aquel hombre que hacía su trabajo en cadena -treinta segundos y una sonrisa más un folleto para los seronegativos, de cinco a quince minutos de conversación "personalizada" para los seropositivos". Así mismo, deja constancia de la falta de tacto de una enfermera. Cuando acude a realizarse las pruebas, la enfermera le pregunta "Cuánto tiempo hace que sabe usted que es seropositivo. La pregunta me sorprendió tanto que fui incapaz de responder".

También tiene cabida en la historia un homeópata, el doctor Lérisson, el cual determina como su diagnóstico la "Espasmofilia", esto es, una carencia de calcio capaz de torturar el cuerpo. El doctor Aron, por su parte, anuncia que el problema recibe el nombre de "Dismorfobia", es decir, que Hervé padecía un odio hacia toda forma de deformidad. Finalmente, Guibert deja su salud en manos del doctor Chandi en Francia y del doctor Otto en sus estancias en Italia, no sin antes afirmas, tras su paso por todos estos especialistas, que "es increíble, esos médicos de barrio están tan hartos de los esputos y de las diarreas de sus pacientes que se dedican a psicoanalizarlos, y hacen luego los diagnósticos más extravagantes...".

Sobre el Dr. Chandi escribe estos párrafos que definen una correcta relación médico-paciente: "El doctor Chandi no pronunciaba un veredicto (...)Lo hacía para ir llevándome, con la mayor suavidad posible, y dejándome a la vez la libertad, como había dicho Muzil, de saber o de engañarme a mí mismo, hacia un nuevo grado de conciencia de mi enfermedad. (...) Decía "No, no he dicho que se trate de una señal decisiva, pero le mentiría ocultándole que se trata de un signo estadístico". Si le preguntaba con pánico: "Entonces ¿es una señal totalmente decisiva?" Él respondía "No, yo no diría eso, pero se trata de una señal bastante determinante".

\section{Pruebas diagnósticas}

En cuanto a pruebas y exploración se refiere, al margen de lo ya comentado, se mencionan, por parte de Chandi, exámenes completos que incluían toma de tensión y auscultación, inspección de las bóvedas plantares, de las hendiduras entre los dedos, revisión de ingle, uretra, vientre, axilas, 
cuello y por debajo de los maxilares; también se revisaban los tejidos que orlaban los nervios. En cuanto a la detección del VIH, Hervé acude al hospital Claude-Bernard para realizarse una extracción de sangre a partir de la cual le podrán afirmar, al fin, si padece SIDA o si todo es fruto de su desasosiego. En contraposición, en la actualidad contamos con cuatro tipos de pruebas para detectar el $\mathrm{VIH}$, cada una con distintas características que quedan recogidas en la siguiente Tabla $1^{22}$.

\section{Tratamientos}

Ante una pandemia se establecen centros de control, diagnóstico y "tratamiento", en lugares en origen no destinados para ello, ya sea el hospital Claude-Bernard o un hospital de campaña de la UME. ¿Cómo se transmite?, ¿quiénes son más vulnerables?; ¿funcionarán los corticoides?... Estas cuestiones se dieron antes y se dan ahora, pues tanto en el siglo XX con el VIH, como ahora en pleno siglo XXI con la COVID-19, no solo nos estamos enfrentando a una pandemia, sino que su causante es desconocido para nosotros. Resulta llamativa la demora en acudir a un centro hospitalario y consultar con un especialista en la materia.
Ya en su momento, el SIDA fue visto como una enfermedad de mucha gravedad por la alta mortalidad que la seguía; si bien el SIDA en nuestra actualidad sigue siendo una patología grave y crónica, una persona puede "sobrevivirla". En la novela se menciona un medicamento "antirretroviral", el AZT (también conocido por Zidovudina, Azidotimidina), el cual "es fabricado hoy industrialmente, comenzó a producirse en 1964 a partir de esperma de arenques y salmones en el marco de la investigación contra el cáncer". En la época que transcurre la novela autobiográfica de Hervé, este fármaco sólo se proporcionaba (pues necesitaba una receta específica) cuando la enfermedad estaba tan avanzada que, en cuanto a supervivencia, no se hablaba de años sino de meses. Actualmente, con un tratamiento adecuado, combinando diferentes familias de antirretrovirales, se alcanza una altísima supervivencia. Podríamos decir que esto es un reflejo de la propia evolución científica, pues lo que antes era simplemente una forma de dar unos meses más de vida a pacientes desahuciados ahora podría ser un tratamiento para salvarles la vida. Es decir, se ha pasado de una mortalidad superior al $90 \%$ de los afectados a la cronificación de la enfermedad.

Si nos centramos en las formas actuales de paliar los efectos del VIH en nuestro organismo

Tabla 1. Relación de pruebas diagnósticas del Sida.

Elaboración propia a partir $\mathrm{de}^{22}$ :

\begin{tabular}{|c|l|}
\hline Prueba de VIH de 3. ${ }^{\text {a generación }}$ & $\begin{array}{l}\text { Consiste en la detección de anticuerpos para VIH-1 y VIH-2 } \\
\text { (anticuerpos que entorno a las } 12 \text { semanas de infección nuestro } \\
\text { organismo genera para hacer frente al virus). }\end{array}$ \\
\hline $\begin{array}{c}\text { Prueba de VIH de 4. }{ }^{\text {a }} \text { generación o Prueba } \\
\text { combinada (Combo) }\end{array}$ & $\begin{array}{l}\text { Es la más utilizada en la sanidad pública, se basa en buscar en } \\
\text { una muestra de sangre tanto los anticuerpos para VIH-1 y VIH-2 } \\
\text { como el antígeno P24 del virus. }\end{array}$ \\
\hline Pruebas rápidas & $\begin{array}{l}\text { Son analíticas de detección de anticuerpos tanto en sangre } \\
\text { como en saliva, con una tardanza de } 30 \text { minutos. }\end{array}$ \\
\hline Técnicas de biología molecular & $\begin{array}{l}\text { Estas pruebas se utilizan para estudios de variabilidad genética, } \\
\text { diagnóstico de recién nacidos, screening de donantes, } \\
\text { seguimiento de personas con VIH, etc. Por lo que no suelen } \\
\text { emplearse para el diagnóstico en sí. }\end{array}$ \\
\hline
\end{tabular}

Rev. Med. Cine. 2020; 16 (e), 453-468 Ediciones Universidad de Salamanca / 
contamos con distintos aliados; si bien cabe recalcar el término "paliar", que no erradicar o curar, pues pese a que nos encontramos en el siglo XXI aún no existe una vacuna efectiva frente a este sigiloso virus. Uno de los tratamientos más efectivos es el tratamiento con antirretrovirales, estos son fármacos diseñados para impedir alguna de las etapas de vida del virus del VIH, evitando así su replicación y con ello logran paliar sus efectos y mejorar la calidad de vida de los afectados. Existen distintas clases: Medicamentos ARV como el AZT, Inhibidores no nucleósidos de la transcriptasa reversa, o NNRTIs; Inhibidores de la proteasa, o IPs y los Inhibidores de la entrada o Inhibidores de la integrasa ${ }^{23}$. De estos antirretrovirales, en la novela se menciona el Retrovir, del que el protagonista dice, "vade retro Satanás".

Actualmente predomina el uso de antirretrovirales de gran actividad, mediante la asociación conocida como TARGA. El tratamiento TARGA se basa en administrar tres o más antirretrovirales que suprimen al máximo la carga viral del paciente, hasta niveles indetectables, recuperando así, en parte, la efectividad del sistema inmune. Por ello se reduce la mortalidad, los costes de atención primaria, el riesgo de infecciones oportunistas, etc. El principal inconveniente es que este tratamiento debe mantenerse de por vida y exige una altísima adherencia por parte del paciente, es decir, este debe ser consciente de la necesidad de tomar sus medicamentos, pues faltar al tratamiento disminuye su efectividad notablemente ${ }^{24}$. En todo caso, la incertidumbre sobre su uso es manifiesta: "Que usted comience a tomarlo ahora o más tarde, que deje de hacerlo mañana y vuelva a tomarlo pasado mañana no tiene la más mínima importancia, porque no se sabe nada sobre ese tema. Se ignora cuándo debe comenzarse el tratamiento y con qué dosis. Quién le diga lo contrario mentirá. Su médico en Francia le prescribe doce cápsulas, yo seis pues hagamos un promedio, digamos ocho al día"-Doctor Otto.
El empeoramiento de Hervé es un hecho latente en la historia, pero no solo se menciona su deterioro, sino también el del trío amoroso del que forman parte Hervé, Jules (ya mencionado) y Berthe. Como ya se ha comentado, otra vía de contagio del VIH es mediante transmisión materno-filial hecho que se da en los hijos de Jules y Berthe, pues se comentan algunos de sus síntomas: "a su regreso precipitado, encontró el cuerpo de su hijo cubierto de erupciones rojas, los ojos hinchados como si estuvieran casi cosidos y las piernas retorcidas por un edema en las rodillas".

Incluso, hay un momento en la historia; que, tanto por su estado anímico y su forma de ser, como por su malestar generalizado en aumento, nuestro protagonista fantasea con el suicidio mediante una sobredosis de Digitalina, agente cardiotónico cuya intoxicación puede provocar la muerte. "De todas formas tú nunca habrías soportado envejecer..."-Bill.

Dado su estado de salud hay constantes idas y venidas a distintos hospitales en distintos países, destacando el hospital Claude-Bernard, el cual quedó destinado a los pacientes de SIDA y cuyo mantenimiento era claramente lamentable: "cuando llegue al único lugar aún vivo en el hospital, que acababa de ser evacuado para destinarse a otra función y que yo atravesaba entre brumas con un hospital fantasma al otro extremo del mundo".

Centrándonos en situaciones concretas, es reseñable una ocasión en la cual en un chequeo rutinario para medir el número de T4 con los que contaba el paciente, dato crucial de cara a optar a una hipotética vacuna o en situación contraria para solicitar el AZT, las enfermeras confundieron las etiquetas de las muestras de Hervé y otro paciente.

A lo largo del texto se alude al medicamento Defenthiol, uno de los primeros con los que se realizaron ensayos clínicos en los enfermos de SIDA, pero que resultó ineficaz, y a una supuesta 
vacuna contra el SIDA, algo que hoy, cuarenta años después, no se ha encontrado.

\section{Actitud y relación afectiva}

Cuando una persona ve próxima su muerte se replantea su vida al completo, cuando un paciente recibe el golpe de realidad que le hace ver que el tiempo no es ilimitado y que ya sea por una enfermedad, por un accidente o por simple vejez va a morir, no tiene tiempo para buscar fama ni reconocimiento. Hervé era artista y como tal entregó sus últimos momentos a escribir sobre lo más importante de su vida, sobre él mismo. Evidentemente Hervé no era ningún santo, pero era humano y uno siente miedo y en su caso se aprecia también una soledad latente. Él mismo relata que no tiene trato con su familia, el único lazo fuerte en el que podría sostenerse era en Jules y Berthe, pero cada vez que veía a su amante veía en sus ojos a un hombre con fecha de muerte marcada por un virus que los unía. También tendría lógica un posible sentimiento de culpa porque, por poder, no solo tenía más que posibilidades de ser la persona que infectó a Jules, sino que fruto de esa infección había dos niños pendiendo de un hilo.

El impacto del diagnóstico es tremendo: "Yo me hallaba como aquel pobre diablo anonadado por el resultado de su análisis, en apariencia de pie, pero en realidad fulminado encima de aquel trozo de acera que no paraba de agrietarse a su alrededor. Sentí una inmensa piedad por nosotros". También su amigo y amante Jules se derrumba: "Creo que Jules, en apariencia tan sólido, sabía, que esa certeza, convirtiéndose en una certeza oficial, a pesar de que siguiera siendo anónima, se había vuelto para él intolerable. (...) Sentir que nuestro amigo, nuestro hermano, se hallaba tan desamparado ante lo que le sucedia era algo físicamente repulsivo".

Las personas que estuvieron cerca de la muerte relatan que en los momentos previos empiezas a dejar de sentir, tu cuerpo ya no es tuyo, las voces que te rodean se alejan y las personas con ellas. Esta fue la vida de Guibert desde el momento en el que confirmó su diagnóstico, su cuerpo dejó de responderle y con él sus cabales en ciertos momentos, se alejó de quien posiblemente más le quería, pero ni muerto en vida uno puede esquivar la traición de "un amigo". Podríamos afirmar que sufrió un deterioro biopsicosocial en toda regla, además de que su propio sistema inmune le destruía.

\section{Aspectos sociales}

Una vez finalizada la lectura se aprecia completamente el reflejo que hace del comienzo de una pandemia, pues incluso podemos extrapolarlo a nuestra realidad. Con el VIH ya lo dijo Muzil en su cama de hospital "es una cosa que debe venirnos de África" y por ello los africanos fueron objeto de rechazo; un símil sería la repulsa contra los chinos "causantes" de la pandemia de la COVID-19.

La estigmatización del VIH ha sido desde su origen muy clara y en el momento narrado este virus se relacionaba directa y exclusivamente con las personas de etnia negra y con los homosexuales como Hervé, pese a que esto no es cierto. Un reflejo de la extensión del virus en la sociedad serían las grandes colas para recibir los resultados de la posible seropositividad o los controles específicos que había que seguir para poder acceder al AZT que Guibert con total dureza describe: "La homosexualidad en este mundo es posible mientras no se hable de ella. Pero no se tolera si es pública". Enunciado que expone el clima de rechazo presente en la década de los ochenta que obligaba a ocultar, no solo la orientación sexual, sino también la enfermedad a los familiares y allegados.

En la lucha contra el estigma y la discriminación, surgieron asociaciones de afectados y voluntarios en defensa de los infectados como la Gay Men Health Crisis (1982) activa en la actualidad o la asociación de ayuda a las víctimas del SIDA que Stéphane, pareja de Muzil, decidió crear en Francia. También se establecieron los 
Principios de Denver (1983) renovados 34 años más tarde en la Declaración de Madrid, donde se reivindican la experiencia de las personas afectadas por VIH como parte fundamental de la respuesta de la infección. Como símbolo de lucha contra el SIDA, en 1991 Frank Moore creo el lazo rojo, emblema utilizado actualmente por gobiernos y ONG en campañas de prevención e información.

Desde un punto de vista político, cabe destacar la creación en 1996 del Programa Conjunto de las Naciones Unidas sobre el VIH y Sida (ONUSIDA) que en 2014 propone la estrategia 90-90-90; el $90 \%$ de las personas que viven con VIH estén diagnosticadas, que el $90 \%$ que conocen su infección tengan acceso al tratamiento y que el $90 \%$ de las personas que lo tengan logren reducir la carga viral ${ }^{5}$.

\section{Repercusión cultural}

La pandemia de VIH no solo ha marcado la vida de aquellas personas que han padecido o padecen SIDA, sino que ha marcado a la sociedad en su totalidad. Este virus ha dejado una gran huella tanto en nuestro cine como en nuestra literatura; ambos ámbitos culturales que no solo han dado voz a aquellos que han querido compartir sus vivencias con este "amigo" tal y como hizo Hervé, sino que también para ayudar a la normalización de una realidad. En cuanto al mundo cinematográfico, podemos destacar una amplia filmografía que dio a conocer ciertos movimientos activistas que lucharon por los derechos de los grupos sociales estigmatizados socialmente como grupos de riesgo. ${ }^{25}$ Películas que tratan el tema del VIH y sus repercusiones son "Philadelphia" (1993), "How to Survive a Plague" (2012), "The Normal Heart" (2014) o "Dallas Buyers Club" (2013). Por ejemplo, en esta última, Matthew McConaughey interpreta a Ron Woodroof, papel que le vale un Óscar a Mejor actor, un hombre de Dallas que es diagnosticado de SIDA y al que le auguran solo un mes de vida; este por distintos factores viaja a México para probar un nuevo fármaco, la dideoxicitina (ddC). Ante los buenos resultados de este fármaco, Ron plantea exportarlo ilegalmente a EE. UU.

En cuanto a la literatura se refiere hay distintas obras en las que la trama gira entorno a personas seropositivas o relacionadas con el $\mathrm{VIH}$, algunos ejemplos son "El paciente ocasional"26, "Más grandes que el amor"27, o "Sero"28. En el libro "Viajes Virales"29 de Lina Meruane, entre otros muchos aspectos del virus se habla de su origen, en plena pandemia cada nación e ideología tenía su propia teoría sobre la aparición o "creación" de este virus letal, pues "mucha gente sospecha que el SIDA es demasiado conveniente para ser mera coincidencia".

La obra "Historia de las enfermedades infecciosas" de José Antonio Maradona, en su apartado "La infección por el VIH y el SIDA" también da una visión interesante al origen del virus, pero en este caso mucho menos conspiranoica ${ }^{30}$.

\section{DISCUSIÓN}

Cuando Rock Hudson hizo público que padecía SIDA, en 1985, meses antes de morir, el mundo empezó a conocer una enfermedad, por aquel entonces mortal, causada por un retrovirus que se denominó virus de la inmunodeficiencia humana (VIH) que atacaba a las células linfocitarias CD4+ provocando, con el tiempo, en el organismo una inmunodeficiencia causando la muerte del individuo aproximadamente a los 6 años de la infección. "Al amigo que no me salvó la vida" escrito por Hervé Guibert, contribuye a conocer en primera persona al $\mathrm{VIH}$, tanto desde un punto de vista biológico como desde el sociocultural; puesto que enfermar no solo implica una alteración morfofuncional del organismo, sino también una alteración de la conducta intrapersonal y las relaciones interpersonales; aspectos que el autor trata con total sinceridad ${ }^{1}$.

Guibert nos describe a través de la novela la evolución de diferentes síntomas, que nos hacen pensar 
que él mismo estaba obsesionado con la aparición de síntomas compatibles con el VIH. También nos narra cómo acude desde a homeópatas a distintos médicos que le dan diagnósticos un tanto dispares; desde la Espasmofilia a la Dismorfobia a tratar con antidepresivos. No fue hasta que le aparecieron los papilomas blancos en la garganta, cuando Hervé decidió hacerse las pruebas de seropositividad, pruebas que dieron positivo y demostraron finalmente al autor que si presentaba la enfermedad.

La novela muestra también cómo se siente Guibert a medida que va evolucionando la enfermedad, desde la esperanza a salvarse hasta el "estoy enmerdado" y las diatribas contra Bill. Narra también los sentimientos de vergüenza y alivio, después de besarle la mano a Muzil en el hospital, acto tras el cual se va a enjabonarse la boca, los mismos sentimientos que tiene cuando "la vieja puta" le metió la lengua hasta el fondo en México. También la sensación de abandono cuando Isabelle Adjani, alias Marine, se marcha a EE. UU. y no se filma la película de Guibert con ella de protagonista o la de ser "una pareja de asesinos salvajes" con Jules mientras penetraban "al Poeta". También es interesante la parte de la novela que dedica a Muzil, que se puede interpretar como una narración de lo que le va a pasar a él en un futuro no tan lejano.

Unos de los aspectos más importantes en la relación médico paciente es la sinceridad, pilar que contribuye a aumentar la veracidad del médico. Cuestiones como el desconocimiento de la enfermedad o de la efectividad del tratamiento deben ser comunicados al paciente, como bien hace el doctor Otto sobre el AZT.

La forma de expresarse y escribir no hace más que reforzar el hecho de que la existencia de la enfermedad no implica que haya que estigmatizar al enfermo, y apartarlo de la sociedad, puesto que el enfermo no es más que una persona que no deja de ser menos humano por el hecho de estarlo $y$ al que hay que seguir tratando como un igual.
Hervé Guibert escribe "Al amigo que no me salvó la vida" a modo de despedida personal en la que quiere contribuir a la normalización de la enfermedad como el VIH y a la no estigmatización del enfermo. Todo ello para hacer ver de la necesidad de sentimiento de humanidad en la sociedad, desde la práctica médica a las prácticas sociales.

Vivimos tiempos difíciles, pero nunca debemos perder nuestra humanidad y mucho menos hacer objeto de discriminación social a personas que padecen. Como se suele decir "mira al pasado, aprende y no vuelvas a cometer los mismos errores". La COVID-19 no es un error. Es una incidencia más ante la que la ciencia esta desarmada, pero terminará controlándola.

\section{CONCLUSIÓN}

"Al amigo que no me salvo la vida" escrita por Hervé Guibert es una historia sobre el VIH, una novela escrita desde la perspectiva del enfermo en donde se expone la dureza de una enfermedad desconocida que provoca la gran epidemia del siglo XX, con millones de afectados y muertos. Una enfermedad que comenzó siendo mortal, pero que, gracias a la investigación y la ciencia, se consigue cronificar hasta el punto de conseguir una carga viral indetectable e intrasmisible. La novela no hace más que recordarnos de la necesidad de invertir en salud y en luchar por la no estigmatización del enfermo. La actual pandemia COVID-19 pone en jaque la sociedad actual, pero aprendiendo del pasado no permitamos que se repitan los mismos errores.

\section{REFERENCIAS}

1. Guibert H. Al amigo que no me salvó la vida. Barcelona: Tusquets Editores; 1991.

2. Grandes pandemias de la historia Historia National Geographic [Internet]. 25 de marzo de 2020. [Consultado: 15 de agosto de 2020].

3. Cuarentena: origen del concepto, qué significa y cuál es su implicancia como medida sanitaria - Instituto de 
Ciencias e Innovación en Medicina [Internet]. 13 de abril de 2020. [Consultado: 15 de agosto de 2020].

4. Ledermann DW. El hombre y sus epidemias a través de la historia. Rev Chil Infect. Edición aniversario. 2003; 20:13-17.

5. Del Amo Valero J, Coiras López MT, Díaz Franco A, Pérez Olmeda MT. La investigación contra la gran epidemia del siglo XX. Madrid: Instituto de Salud Carlos III; 2017.

6. Miranda Gómez O, Nápoles Pérez M. Historia y teorías de la aparición del virus de la inmunodeficiencia humana. Rev Cub Med Mil. 2009; 38(3-4) 63-72.

7. La perturbadora delicadeza de Hervé Guibert. Babelia. El País [Internet]. 19 de julio de 2019. [Consultado: 23 de agosto de 2020].

8. Hervé Guibert - Wikipedia, la enciclopedia libre [Internet]. 22 de agosto de 2020. [Consultado: 24 de agosto de 2020].

9. Cantabrana B, González-Rodríguez S, Hidalgo A. Una literatura de la enfermedad y de la muerte. Rev Med Cine 2016;12(1): 47-59.

10. Montagnier L. Las batallas de la vida. Mejor prevenir que curar. Madrid: Alianza Editorial, S.A; 2009.

11. Santana A, Domínguez C, Lemes A, Molero T, Salido E. Biología celular y molecular del virus de inmunodeficiencia humana (VIH). Rev Diagn Biol 2003; 52(1): 7-18.

12. Murray $P$, Rosenthal K, Pfaller M. Microbiología médica. 5th ed. Madrid: Elsevier España; 2006

13. Soto Ramírez L.E. Mecanismos patogénicos de la infección por VIH. Rev Invest Clín 2004; 56(2): 143-52.

14. Delgado R. Virological characteristics of HIV. Enferm Infecc Microbiol Clin 2011;29(1):58-65.

15. Dan L, Anthony S, Dennis L, Stephen L, Larry J, Jameson JL. Harrison: principios de medicina interna. 19th ed. Dan L, Anthony S, Dennis L, Stephen L, Larry J. Jameson JL, (Eds). McGraw-Hill Interamericana; 2012.p 1215-30.

16. Lumbreras Bermejo C, Rubio García R. Fármacos antivíricos. En Lorenzo P, Moreno A, Lizasoain I, Leza JC, Moro M.A, Portolés A (Eds.). Velázquez. Farmacología Básica y Clínica. 19a Ed. Madrid: Eitorial Médica Panamericana; 2017.p.857-889.
17. Cruz Roja.es [Internet]. España: Cruz Roja Española, Inc. Síntomas del sida-Información sobre sida (aprox. 1 pantalla). 2008. [Consultado: 18 de agosto de 2020].

18. Laguado LD, Rodríguez Amaya RM, Gómez J, Bonilla RA, Rojas HG. Endoscopic and Pathological Findings in Patients with HIV and Digestive Symptoms at a University Hospital. Rev Col Gastroenterol [Internet]. 2016; 31(2): 111-8.

19. Escribano-Bermejo M, Bascones-Martínez A. Leucoplasia oral: Conceptos actuales. Av Odontoestomatol 2009; 25(2): 83-97.

20. Vademecum.es- Su fuente de conocimiento farmacológico [Internet]. 3 de diciembre de 2010. [Consultado: 31 de agosto de 2020].

21. CIMA. Centro de información de medicamentos [Internet]. [Consultado: 31 de agosto de 2020].

22. Cruz Roja.es [Intenet]. España: Cruz Roja Española, Inc. Prueba detección del VIH-Prueba del VIH (aprox. 1 pantalla). 2008. [Consultado: 18 de agosto de 2020].

23. Aidsinfo.org [Internet] International association of providers of aids care, Inc. Terapia Antirretroviral (TARV) (aprox. 1 pantalla). 23 de julio de 2014. [Consultado: 20 de agosto de 2020].

24. Pacífico J, Gutierrez C. Información sobre la medicación y adherencia al tratamiento antirretroviral de gran actividad en pacientes con VIH/SIDA de un hospital de Lima, Perú. Rev Peru Med Exp Salud Publica 2015;32(1):66-72.

25. Clua García R, Mestres Camps L, de Dios Sánchez R, Terradas Robledo R. Los movimientos activistas del VIH / sida en el cine Resumen HIV/AIDS activist movements in movies. Rev Med Cine 2020; 16(2):111-21.

26. Larrazabal I, Reig R. El paciente ocasional. Barcelona: Ediciones Península; 2011.

27. Dominique L. Más grandes que el amor. $25^{\mathrm{a}} \mathrm{Ed}$. Barcelona: Seix Barral; 1990.

28. Larrazabal Arrate I. Sero. Madrid: Grupo Odisea; 2008.

29. Meruane L. Viajes Virales. Santiago de Chile: Fondo de Cultura Económica; 2012.

30. Maradona Hidalgo JA. Historia de las enfermedades infecciosas. Oviedo: Servicio de publicaciones de la Universidad de Oviedo; 2010. 398 p. 




